High-mobility group box 1 (HMGB1) is a versatile protein with nuclear and extracellular functions. In the extracellular milieu, HMGB1 binds to several receptors, notably the receptor for advanced glycation end-products (RAGE). The expressions of HMGB1 and RAGE have been described in a variety of cancers. However, the clinical values of HMGB1 and RAGE in haematological malignancies have yet to be evaluated. A systematic search through PubMed and the Web of Science for articles discussing the role of HMGB1 and RAGE in haematological malignancies produced 15 articles. Overexpression of HMGB1 was reported to be associated with malignancy and, in certain studies, poor prognosis and tumour aggressiveness. Only one included study investigated the clinical value of RAGE, in which no significant difference was found between expression of RAGE in CLL neoplastic cells and nonmalignant controls. The discussed associations of HMGB1 and RAGE with clinicopathological characteristics of patients with haematological malignancies warrants further investigation into the prognostic and diagnostic value of both of these molecules.

Key words: HMGB1, RAGE, hematological malignancies, leukemia, lymphoma.

Contemp Oncol (Pozn) 2016; 20 (6): 425-429 DOI: https://doi.org/10.5114/wo.2016.65600

\section{Association of high mobility group BOX-1 and receptor for advanced glycation endproducts with clinicopathological features of haematological malignancies: a systematic review}

Austin H. Nguyen ${ }^{1}$, Sheila B. Bhavsar ${ }^{1}$, Erinn M. Riley ${ }^{1}$, Gabriel C. Caponetti², Devendra K. Agrawal ${ }^{1}$

1Department of Clinical and Translational Science, Creighton University School of Medicine, Omaha NE, United States

${ }^{2}$ Department of Pathology and Laboratory Medicine, Perelman School of Medicine, University of Pennsylvania, Philadelphia, PA, United States

\section{Introduction}

High-mobility group box 1 (HMGB1) is a highly conserved and ubiquitous protein found in eukaryotic cells. Structurally, HMGB1 consists of 215-amino acid polypeptide organised into two DNA-binding domains and a negatively charged C-terminal tail [1, 2]. This molecule exhibits dual functionality as a non-histone nuclear protein and also an inflammatory cytokine, extracellularly [3]. HMGB1 can be released passively by damaged or necrotic cells or actively by immune cells and stressed cancer cells [4-8]. Extracellular HMGB1 binds to several cell surface receptors, including the Receptor for Advanced Glycation End products (RAGE) and the Triggering Receptor Expressed on Myeloid cells 1 (TREM-1) $[9,10]$.

RAGE is a transmembrane receptor belonging to the immunoglobulin superfamily that binds to advanced glycation endproducts. RAGE is mostly stimulated by cellular stress, such as inflammation, and is found to be over-expressed in many diseases, including numerous malignancies [11]. The interaction between HMGB1 and RAGE has also been studied in different cancers. HMGB1 binding to RAGE may activate signalling pathways, such as Ras/MAKP, PI3K/AKt, and NF-kB, leading to over-expression of certain genes and a change in tumour cell biological behaviour [12]. Additionally, HMGB1 and RAGE play important roles in the development, growth and metastasis of multiple tumours $[13,14]$. In a murine lung cancer model, blockade of HMGB1 and RAGE signalling suppressed tumour growth and metastasis [15].

Several malignancies, including haematopoietic ones, are known to arise in association with infection and chronic inflammation. An inflammatory microenvironment may aid in the development of neoplastic processes and foster its proliferation, survival, and migration [16]. As such, HMGB1 has been extensively studied in various cancers due to its association with inflammation. Previous studies have identified the roles of HMGB1 in cancer, with increased protein expression in colon, breast, lung, prostate, cervical and gastric cancer and hepatocellular carcinoma when compared with normal tissues and healthy controls [7, 17]. Furthermore, recent investigations have demonstrated the capacity of HMGB1 to promote angiogenesis [12, 18]. To our knowledge, however, a systematic evaluation of the clinical value of HMGB1 and RAGE in haematological malignancies has not been performed to date. The present study systematically reviews the available literature re- 
garding HMGB1 and RAGE in haematological malignancies and evaluates its potential clinical value.

\section{Methods}

The following terms were used in a systematic search of PubMed and the Web of Science: leukaemia, lymphoma, non-Hodgkin's lymphoma, and haematological malignancies with HMGB1 or RAGE. Article titles and abstracts were screened, with full-text review ultimately determining inclusion status. Only articles in English discussing original studies investigating the clinical utility of HMGB1 and RAGE in human haematological malignancies were included.

\section{Results}

Searches of PubMed and the Web of Science returned 53 and 78 articles, respectively (Fig. 1). After screening ti-

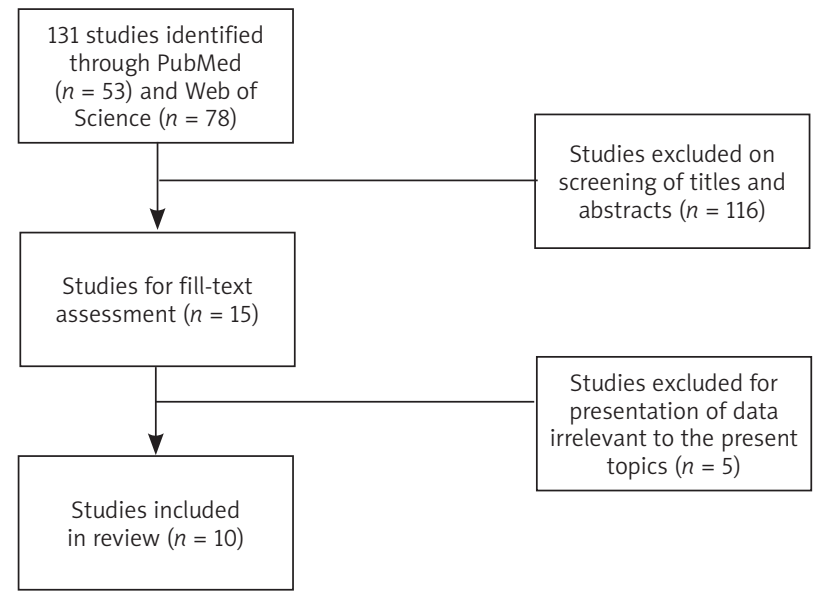

Fig. 1. Systematic search of PubMed and the Web of Science returned a total of 131 studies. After review of titles, abstracts, and full-text, 10 studies were included in this review tles and abstracts, the full-text of 15 articles were retrieved for further review to include in the study. Five articles were excluded due to insufficient or inapplicable data, leaving a final ten articles to be included in this review.

The included articles demonstrated a great deal of variability in the type of haematological malignancy studied. The characteristics of each study are summarised in Table 1, with major findings summarised in Table 2. Malignancies of B-cell origin were the most commonly studied, including non-Hodgkin's lymphoma (NHL) [19-21] and lymphocytic leukaemias [22-24]. A minority of studies investigated HMGB1 and RAGE in T-cell malignancies [25, 26] and acute myeloid leukaemia (AML) [27, 28].

The study by Court et al. [27] observed significantly higher expression of HMGB1 in AML samples than in controls (microarray, $p=0.009$; Southern blot, $p<0.001$ ). Separately, a comparison of 31 newly diagnosed AML patients to 12 relapsed/refractory patients using real-time PCR demonstrated a significantly increased expression in the relapsed/refractory group $(p=0.005)$ [28]. Interestingly, HMGB1 expression was found to be a target of and inversely correlated with levels of microRNA-181b. This microRNA plays a role in the regulation of activated $B$ cells and has been shown to be down-regulated in chronic lymphocytic leukaemia (CLL), it decreases with progression of CLL, and it is associated with survival in CLL patients [2931]. This early evidence is suggestive of a role of HGMB1 in the development and progression of AML.

An investigation of HMGB1 expression in various B-cell leukaemias and lymphomas was performed in four studies. Xu et al. [22] demonstrated HMGB1 mRNA and protein levels to be higher in bone marrow samples of patients with acute lymphocytic leukaemia, when compared with lymphocytes from healthy individuals used as controls. In CLL patients [23], plasma levels of HMGB1 were highest in those with progressive relapsed disease, and they correlat-

Table 1. Summary of characteristics of included studies investigating HMGB1 and RAGE

\begin{tabular}{|c|c|c|c|c|c|c|}
\hline Study & Neoplasm & Sample & $N$ (total) & $N$ (malignant) & $\begin{array}{l}\text { Mean Age } \\
\text { (range) }\end{array}$ & $\begin{array}{c}\text { Gender } \\
M: F\end{array}$ \\
\hline Court et al. (2004) & AML & Bone marrow & 18 & 11 & $64^{a}(21-75)$ & - \\
\hline Xu et al. (2004) & ALL & Bone marrow & 28 & 28 & - & - \\
\hline Meyer et al. (2008) & $\mathrm{NHL}{ }^{\mathrm{b}}$ & FFPE & 24 & 18 & $50.9(17-87)$ & $8: 6^{*}$ \\
\hline Zappasodi et al. (2010) & $\mathrm{BCL}$ & $\begin{array}{l}\text { Lymphoma cells from LN or } \\
\text { blood }\end{array}$ & 14 & 14 & $58.2(45-72)$ & $10: 4$ \\
\hline Nomura et al. (2011) & Various & Serum & 45 & 45 & $54^{\mathrm{a}}(21-78)$ & $27: 18$ \\
\hline Mao et al. (2012) & T cell lymphoma & FFPE biopsy & 142 & 102 & $56(14-81)$ & $60: 42$ \\
\hline Inoue et al. (2013) & Various ${ }^{c}$ & Serum & 54 & 54 & $61^{a}(26-77)$ & $32: 22$ \\
\hline Jia et al. (2014) & $C L L$ & $\begin{array}{l}\text { Plasma \& } \\
\text { FFPE LN biopsy }\end{array}$ & $\begin{array}{l}60 \text { (plasma) } \\
144(\mathrm{LN})\end{array}$ & $\begin{array}{l}60 \text { (plasma) } \\
86(\mathrm{LN})\end{array}$ & - & - \\
\hline Kimura et al. (2014) & Adult ATLL & Plasma & 13 & 8 & & \\
\hline Lu et al. (2014) & AML & Bone marrow aspirate & 43 & 43 & $46^{a}(13-80)$ & $20: 23$ \\
\hline
\end{tabular}

*Not all reported.

a Median. ${ }^{b} D L B C L(n=8)$, anaplastic large T cell lymphoma $(n=1)$, follicular lymphoma $(n=6)$, small lymphocytic lymphoma $(n=2)$, nodal marginal zone $B C L(n=1)$. 'AML $(n=18)$, ALL $(n=5), D L B C L(n=7)$, follicular lymphoma $(n=5)$, angioimmunoblastic T cell lymphoma $(n=1)$, myelodysplastic syndrome $(n=8)$, multiple myeloma $(n=5)$, ATLL $(n=1)$, complicated hematopoietic stem cell transplant patient $(n=4)$.

ALL - acute lymphocytic leukemia; $A M L$ - acute myeloid leukemia; $A T L L$ - acute T cell leukemia/lymphoma; BCL - B cell lymphoma; CLL - chronic lymphocytic leukemia; DLBCL - diffuse large B cell lymphoma; FFPE - formalin-fixed paraffin-embedded; NHL - non-Hodgkin lymphoma 
Table 2. Clinical significance of HMGB1 and RAGE in hematologic malignancies

\begin{tabular}{|c|c|c|c|}
\hline Study & Neoplasm & Assay & Clinical significance \\
\hline $\begin{array}{l}\text { Court et al. } \\
(2004)\end{array}$ & AML & $\begin{array}{l}\text { cDNA microarray, } \\
\text { real-time PCR, } \\
\text { Southern blot }\end{array}$ & $\begin{array}{l}\text { AML patient samples exhibited significantly higher expression of HMGB1 than controls } \\
(p=0.009)\end{array}$ \\
\hline $\begin{array}{l}\text { Xu et al. } \\
(2004)\end{array}$ & ALL & $\begin{array}{l}\text { qRT-PCR, Western } \\
\text { blot }\end{array}$ & $\begin{array}{l}\text { HMGB1 mRNA and protein levels were increased in ALL specimens when compared to } \\
\text { normal lymphocytes }\end{array}$ \\
\hline $\begin{array}{l}\text { Meyer et al. } \\
(2008)\end{array}$ & $\mathrm{NHL}$ & qRT-PCR, IHC & $\begin{array}{l}\text { HMGB1 level was higher in 11/18 lymphoma samples, compared with the average of the } \\
\text { controls } \\
\text { In positive samples, HMGB1 was localized to the nucleus and specifically in lymphoma } \\
\text { cells, not surrounding cells }\end{array}$ \\
\hline $\begin{array}{l}\text { Zappasodi } \\
\text { et al. (2010) }\end{array}$ & $\mathrm{NHL}$ & ELISA & $\begin{array}{l}\text { HMGB1 release from treated tumor cells did not statistically differ by treatment } \\
\text { (doxorubicin, UVC, } \gamma \text { irradiation, and HS, single or combined), suggesting much variation } \\
\text { in ability to emit immunogenic signaling in lymphoma cells }\end{array}$ \\
\hline $\begin{array}{l}\text { Nomura } \\
\text { et al. }(2011)\end{array}$ & Various $^{a}$ & ELISA & $\begin{array}{l}\text { Patients with DIC associated with hematologic malignancy exhibited a decrease in } \\
\text { serum HMGB1 after rTM therapy }(p<0.001) \\
\text { HMGB1 correlated with other serum markers including prothrombin time, fibrinogen, } \\
\text { C-reactive protein, IL-6, and TNF- } \alpha(\text { all, } p<0.05)\end{array}$ \\
\hline $\begin{array}{l}\text { Mao et al. } \\
(2012)\end{array}$ & $\begin{array}{l}\text { T cell } \\
\text { lymphoma }\end{array}$ & $\mathrm{IHC}$ & $\begin{array}{l}\text { HMGB1 was present in the cytosol in } 72 \%(n=65) \text { lymphoma cases vs. } 45 \%(n=18 / 40) \\
\text { of reactive lymphoid hyperplasia controls }(p<0.05) \\
\text { Overexpression of HMGB1 was associated with tumor aggressiveness }(p<0.001) \text { and } \\
\text { clinical stage }(p<0.001)\end{array}$ \\
\hline $\begin{array}{l}\text { Inoue et al. } \\
(2013)\end{array}$ & Various $^{b}$ & ELISA & $\begin{array}{l}\text { NSD in serum HMGB1 between patients in complete remission vS. refractory malignancy } \\
\text { Malignancy complicated by SIRS had significantly higher serum HMGB1 compared with } \\
\text { patients in remission }(p=0.001) \text { or with refractory malignancy }(p=0.08) \\
\text { Resolution of SIRS }(n=13) \text { led to decreased serum HMGB1 } \\
\text { High HMGB1 in SIRS cancer patients was associated with early death within } 1 \text { month } \\
(p=0.016)\end{array}$ \\
\hline $\begin{array}{l}\text { Jia et al. } \\
(2014)\end{array}$ & $\mathrm{CLL}$ & $\begin{array}{l}\text { Plasma: ELISA } \\
\text { LN: TMA, IHC }\end{array}$ & $\begin{array}{l}\text { Plasma HMGB1 levels correlated with acute lymphocyte count }(p<0.0001) \\
\text { Decreased LN HMGB1 overall ( } p<0.0001) \text {, but increased cytoplasmic expression } \\
\text { Increased HMGB1-containing cells in LN was associated with shorter overall survival } \\
(p=0.03) \\
\text { RAGE is strongly expressed in LN of patients with CLL }\end{array}$ \\
\hline $\begin{array}{l}\text { Kimura et al. } \\
(2014)\end{array}$ & ATLL & ELISA & HMGB1 tended to be higher in ATLL plasma than healthy controls $(p=0.051)$ \\
\hline $\begin{array}{l}\text { Lu et al. } \\
\text { (2014) }\end{array}$ & AML & $\begin{array}{l}\text { qRT-PCR, Western } \\
\text { blot }\end{array}$ & $\begin{array}{l}\text { Increased HMGB1 expression in relapsed/refractory AML patients compared to newly } \\
\text { diagnosed patients }(p<0.05)\end{array}$ \\
\hline
\end{tabular}

${ }^{a} D L B C L(n=8)$, anaplastic large T cell lymphoma $(n=1)$, follicular lymphoma $(n=6)$, small lymphocytic lymphoma $(n=2)$, nodal marginal zone $B C L(n=1)$ ${ }^{b} A M L(n=18), A L L(n=5), D L B C L(n=7)$, follicular lymphoma $(n=5)$, angioimmunoblastic T cell lymphoma $(n=1)$, myelodysplastic syndrome $(n=8)$, multiple myeloma $(n=5)$, adult ATLL $(n=1)$, complicated hematopoietic stem cell transplant patient $(n=4)$.

$A L L$ - acute lymphocytic leukemia; $A M L$ - acute myeloid leukemia; $A T L L$ - acute T cell lymphocytic leukemia; BCL - B cell lymphoma; CLL - chronic lymphocytic leukemia; DLBCL - diffuse large B cell lymphoma; NHL - non-Hodgkin lymphoma; NSD - no significant difference; qRT-PCR - quantitative real-time polymerase chain reaction; rTM - recombinant thrombomodulin; SIRS - systemic inflammatory response syndrome; TMA - tissue microarray

ed with lymphocyte counts in CLL samples $(p<0.0001)$. In the same study, evaluation of formalin-fixed, paraffin-embedded lymph node biopsies from CLL patients demonstrated tissue HMGB1 expression to be decreased in the nucleus and increased in the cytoplasm $(p<0.001)$. Overall HMGB1 expression in CLL patients was decreased, when compared to reactive lymph node controls $(p<0.001)$. Interestingly, while decreased overall intratumoural HMGB1 expression was associated with a poor prognosis, an increase in the number of cells expressing HMGB1 in the cytoplasm was also associated with shorter survival $(p=0.0303)$. Additionally, this was the only included study to concurrently investigate RAGE. Immunohistochemical evaluation demonstrated RAGE to be similarly expressed in the microenvironment stromal cells in both CLL tissue and controls.
Meyer et al. [19] analysed the expression of HMGB1 using reverse transcription $P C R$ and immunohistochemistry in lymph nodes from patients with various types of $\mathrm{NHL}$, including diffuse large B-cell lymphoma (DLBCL; $n=8$ ), anaplastic large T-cell lymphoma $(n=1)$, follicular lymphoma $(n=6)$, small lymphocytic lymphoma $(n=2)$, and marginal zone lymphoma $(n=1)$. Levels of HMGB1 mRNA in lymphoma samples demonstrated marked variability with no correlation by malignant grade, though 11 of the $18 \mathrm{NHLs}$ expressed higher levels than the average of the benign lymph node controls. HMGB1 protein expression was observed to be restricted to the lymphoma cells in the tissue sections. Another study [24] investigating HMGB1 release from lymphoma cells observed similar variability in HGMB1 levels. Primary lymphoma cells were isolated from peripheral blood or lymph nodes of patients with lympho- 
plasmacytic or follicular lymphoma. When comparing cells from patients who responded to immunotherapy (vaccination with autologous monocyte-derived DCs pulsed with autologous tumour cells dying after exposure to heat shock, $\gamma$-ray, and UVC ray) with nonresponders, no significant difference in HMGB1 release was observed. While this study investigates the use of HMGB1 as a marker for response to therapy, further studies are needed on response to more conventional therapeutic modalities.

Evaluation of serum from patients with various types of lymphoma was performed in two studies [20, 21]. Nomura et al. [20] explored the role of HMGB1 as a marker for disseminated intravascular coagulation (DIC) in patients with haematological malignancies. In patients with DIC, numerous platelet activation markers correlated with HMGB1 levels, including prothrombin time, fibrinogen, and C-reactive protein. Additionally, HMGB1 levels significantly decreased after recombinant thrombomodulin therapy $(p<0.001)$. This study was limited by its non-comparative design. However, it did form the basis for further investigation regarding the possible value of HGMB1 as a biomarker for the outcome and development of complications in patients with haematological malignancy. Another study [21] investigated the role of HMGB1 in the development of systemic inflammatory response syndrome (SIRS) in patients with haematological malignancies. Included patients were classified as cases with complete remission, no remission, or cases complicated by SIRS. Serum HMGB1 did not differ by remission status, but was found to be significantly higher in cases complicated by SIRS, compared to cases of no remission and cases of complete remission $(p<0.001$ and $p=0.008$, respectively). Serum HMGB1 was seen to decrease in cases with improvement of SIRS ( $p=0.047)$, whereas higher serum HMGB1 levels were associated with earlier mortality $(p=0.016)$.

Two included studies investigated the clinical value of HMGB1 in T-cell-derived haematological malignancies [25, 26]. Plasma HMGB1 levels collected upon admission from patients diagnosed with adult T-cell leukaemia tended to be higher than those of healthy donors ( $p=0.051)$ [25]. While this study was affected by a small sample size (total, $n=$ 13), the mean level of HMGB1 in patients with T-cell leukaemias was over ten-fold higher than that of healthy donors. In another study [26] immunohistochemical evaluation of 102 formalin-fixed, paraffin-embedded T-cell lymphoma specimens similarly demonstrated HMGB1 expression to be more frequently expressed in lymphoma tissue than in biopsies of reactive lymphoid hyperplasia $(p<0.01)$. No correlation was found between expressions of HMGB1 and gender, age, or tumour location. Overexpression of HMGB1 was found to be associated with tumour aggressiveness $(p<0.001)$, graded according to the 2008 WHO Classification of Tumours of Haematopoietic and Lymphoid Tissue, with low-grade, aggressive, and highly-aggressive tumours positively expressing HMGB1 in $32.3 \%, 71.4 \%$, and $100 \%$ of the cases, respectively. HMGB1 was also associated with tumour stage ( $p<0.001)$, with expression being observed in $49.3 \%$ of stage I/II lymphomas and in $96.8 \%$ of stage III/ IV lymphomas.

\section{Discussion}

The included studies exhibited marked variation in the type of haematological malignancy and the clinical aspect studied. There is a marked paucity in the literature, particularly with regards to studies investigating the clinical value of RAGE in haematological malignancies. However, the studies that evaluated HMGB1 concur in that this molecule is aberrantly expressed in patients with haematological malignancies. While the majority of studies suggest HMGB1 levels to be increased in malignant conditions, when compared to controls, Jia et al. [23] observed an overall decrease in lymph node HMGB1 expression, but a marked increase in the number of cells exhibiting cytoplasmic expression. This could be due to the dual function of HGMB1 as a nuclear structural protein and as an inflammatory signalling molecule [3], with a shift toward the latter in cancerous states.

Overall, the included studies offer incipient evidence on the clinical value of HMGB1 in haematological malignancies. Numerous avenues for future research pursuit are raised, rather than confirming any specific clinical use for HMGB1. Only one included study investigated the potential relationship between HMGB1 expression and survival [23]. The predictive value of HMGB1 in patient survival is still unclear, and further exploration is warranted.

Zappasodi et al. [24] investigated HMGB1 levels as a marker for response to immunotherapy. However, study on the value of HMGB1 in more conventional chemotherapy and/or radiotherapy modalities, should be performed. In lower rectal cancer, HMGB1 immunostaining was previously shown to correlate with resistance of preoperative chemoradiotherapy, with higher expression indicating a poorer response to chemoradiotherapy [32]. Such investigation could prove useful in clinical prediction of response to therapy in patients with haematological malignancies. Moreover, HMGB1 has a potential role as a biomarker for the prediction of certain complications seen in these patients. Early evidence is suggestive of a role of HMGB1 in DIC [20] and SIRS [21], although to date no large retrospective study nor prospective trial has been performed.

Lastly, HMGB1 offers potential for the development of targeted therapies. Its suggested role in oncogenesis and tumour progression [17] makes it an attractive target for adjuvant therapy. In vitro blockade of HMGB1 signalling using anti-HMGB1 and anti-RAGE antibodies inhibited differentiation of CLL cells into nurse-like cells, a cellular phenotype associated with shorter overall survival in CLL patients.

\section{Conclusions}

Early research on HMGB1 and RAGE is highly encouraging and suggestive, making further investigation of these venues promising. The current literature suggests that there is potential for the application of these molecules in multiple clinical modalities.

This work was supported by the Department of Clinical and Translational Science of Creighton University School of Medicine.

The authors declare no conflict of interest. 


\section{References}

1. Cheng BQ, Jia CQ, Liu CT, Lu XF, Zhong N, Zhang ZL, Fan W, Li YQ. Serum high mobility group box chromosomal protein 1 is associated with clinicopathologic features in patients with hepatocellular carcinoma. Dig Liver Dis 2008; 40: 446-52.

2. Lee H, Song M, Shin N, Shin CH, Min BS, Kim HS, Yoo JS, Kim H. Diagnostic significance of serum hmgb1 in colorectal carcinomas. PLoS One 2012; 7: e34318.

3. Czura CJ, Wang H, Tracey KJ. Dual roles for HMGB1: DNA binding and cytokine. J. Endotoxin Res 2001; 7: 315-21.

4. Gardella S, Andrei C, Ferrera D, Lotti LV, Torrisi MR, Bianchi ME, Rubartelli A. The nuclear protein HMGB1 is secreted by monocytes via a non-classical, vesicle-mediated secretory pathway. EMBO Rep 2002; 3: 995-1001.

5. Scaffidi P, Misteli T, Bianchi ME. Release of chromatin protein HMGB1 by necrotic cells triggers inflammation. Nature 2002; 418: 191-5.

6. Rovere-Querini P, Capobianco A, Scaffidi P, et al. HMGB1 is an endog enous immune adjuvant released by necrotic cells. EMBO Rep 2004; 5: 825-30.

7. Sims GP, Rowe DC, Rietdijk ST, Herbst R, Coyle AJ. HMGB1 and RAGE in inflammation and cancer. Annu Rev Immunol 2010; 28: 367-88.

8. Guo ZS, Liu Z, Bartlett DL, Tang D, Lotze MT. Life after death: targeting high mobility group box 1 in emergent cancer therapies. Am J Cancer Res 2013; 3: 1-20.

9. Hori O, Brett J, Slattery T, et al. The receptor for advanced glycation end products (RAGE) is a cellular binding site for amphoterin. Mediation of neurite outgrowth and co-expression of rage and amphoterin in the developing nervous system. J Biol Chem 1995; 270: 25752-61.

10. Nguyen AH, Berim IG, Agrawal DK. Chronic inflammation and cancer: emerging roles of triggering receptors expressed on myeloid cells. Expert Rev Clin Immunol 2015; 11: 849-57.

11. Chuah YK, Basir R, Talib H, Tie TH, Nordin N. Receptor for advanced glycation end products and its involvement in inflammatory diseases. Int J Inflam 2013; 2013: 403460.

12. Schlueter C, Weber H, Meyer B, Rogalla P, Röser K, Hauke S, Bullerd iek J. Angiogenetic signaling through hypoxia: HMGB1: an angiogenetic switch molecule. Am J Pathol 2005; 166: 1259-63.

13. Srinivasan M, Banerjee S, Palmer A, et al. HMGB1 in hormone-related cancer: a potential therapeutic target. Horm Cancer 2014; 5: 127-39.

14. Diener KR, Al-Dasooqi N, Lousberg EL, Hayball JD. The multifunction al alarmin HMGB1 with roles in the pathophysiology of sepsis and cancer. Immunol Cell Biol 2013; 91: 443-50.

15. Taguchi A, Blood DC, del Toro G, et al. Blockade of RAGE-amphoterin signalling suppresses tumour growth and metastases. Nature 2000; 405: 354-60.

16. Lin W, Karin M. A cytokine-mediated link between innate immunity, inflammation, and cancer. J Clin Investig 2007; 117: 1175-83.

17. Tang D, Kang R, Zeh HJ 3rd, Lotze MT. High-mobility group box 1 and cancer. Biochim Biophys Acta 2010; 1799: 131-40.

18. Mitola S, Belleri M, Urbinati C, Coltrini D, Sparatore B, Pedrazzi M, Melloni E, Presta M. Cutting edge: extracellular high mobility group box-1 protein is a proangiogenic cytokine. J Immunol 2006; 176: 12-5.

19. Meyer A, Staratschek-jox A, Springwald A, Wenk H, Wolf J, Wickenhauser C, Bullerdiek J. Non-Hodgkin lymphoma expressing high lev els of the danger-signalling protein HMGB1. Leuk Lymphoma 2008 . 49: 1184-9.

20. Nomura S, Fujita S, Ozasa R, Nakanishi T, Miyaji M, Mori S, Ito T, Ishii K. The correlation between platelet activation markers and HMGB1 in patients with disseminated intravascular coagulation and hematologic malignancy. Platelets 2011; 22: 396-7.

21. Inoue Y, Saito T, Ogawa K, et al. Role of serum high mobility group box 1 in hematological malignancies complicated with systemic inflammatory response syndrome and effect of recombinant thrombomodulin. Leuk Lymphoma 2013; 54: 1953-8.

22. Xu Y, Sumter TF, Bhattacharya R, Tesfaye A, Fuchs EJ, Wood LJ, Huso DL, Resar LM. The HMG-I oncogene causes highly penetrant, ag gressive lymphoid malignancy in transgenic mice and is overexpressed in human leukemia. Cancer Res 2004; 64: 3371-5.
23. Jia L, Clear A, Liu FT, et al. Extracellular HMGB1 promotes differentiation of nurse-like cells in chronic lymphocytic leukemia. Blood 2014; 123: 1709-19.

24. Zappasodi R, Pupa SM, Ghedini GC, et al. Improved clinical outcome in indolent B-Cell lymphoma patients vaccinated with autologous tumor cells experiencing immunogenic death. Cancer Res 2010; 70: 9062-73.

25. Kimura R, Mori N. Abundant expression of HMGB1 in human T-cell lymphotropic virus type I-infected T-cell lines and high plasma levels of HMGB1 in patients with adult T-cell leukemia. Oncol Lett 2014; 7: 1239-242.

26. Mao X, Wang G, Chen Z, Wang LN, Zhang JB, Wang HL. Expression of HMGB1 and its Clinical Significance in T-cell Lymphoma. Asian Pacific J Cancer Prev 2012; 13: 5569-71.

27. Court EL, Smith MA, Avent ND, Hancock JT, Morgan LM, Gray AG, Smith JG. DNA microarray screening of differential gene expression in bone marrow samples from AML, non-AML patients and AML cell lines. Leuk Res 2004; 28: 743-53.

28. Lu F, Zhang J, Ji M, et al. miR-181b increases drug sensitivity in acute myeloid leukemia via targeting HMGB1 and Mcl-1. Int J Oncol 2014; 45: 383-92.

29. Marton S, Garcia MR, Robello C, et al. Small RNAs analysis in CLL reveals a deregulation of miRNA expression and novel miRNA candidates of putative relevance in CLL pathogenesis. Leukemia 2008; 22: 330-8.

30. Visone R, Veronese A, Rassenti LZ, et al. miR-181b is a biomarker of disease progression in chronic lymphocytic leukemia. Blood 2011; 118: 3072-9.

31. Li S, Moffett HF, Lu J, et al. MicroRNA expression profiling identifies activated $B$ cell status in chronic lymphocytic leukemia cells. PLoS One 2011; 6: e16956.

32. Hongo K, Kazama S, Tsuno NH, et al. Immunohistochemical detection of high-mobility group box 1 correlates with resistance of preoperative chemoradiotherapy for lower rectal cancer: a retrospective study. World J Surg Oncol 2015; 13: 7.

\section{Address for correspondence}

\section{Austin H. Nguyen}

Department of Clinical and Translational Science

Creighton University School of Medicine

2500 California Plaza

68102 Omaha

United States

e-mail: AustinNguyen@creighton.edu

Submitted: 5.03 .2016

Accepted: 1.08 .2016 